\title{
Endoreversible Performance Analysis of a modified dual cycle and comparison with the classical engine cycles
}

\author{
Huseyin Sahin ${ }^{1 *}$, Guven Gonca ${ }^{2}$ \\ 1* Uskudar American Academy, Uskudar, İstanbul, Turkey, (ORCID: 0000-0003-2071-3350), hsahin22@my.uaa.k12.tr \\ 2 Yildiz Technical University, Naval Arch. and Marine Eng. Depart, Besiktas, İstanbul, Turkey, (ORCID: 0000-0001-6293-6128), ggonca@ yildiz.edu.tr
}

(First received 28 September 2021 and in final form 30 November 2021)

(DOI: 10.31590/ejosat.1016058)

ATIF/REFERENCE: Sahin, H. \& Gonca, G. (2021). Endoreversible Performance Analysis of a modified dual cycle and comparison with the classical engine cycles. European Journal of Science and Technology, (27), 1003-1009.

\begin{abstract}
In this study, energetic performance analysis of an endoreversible modified dual cycle is performed. In this context, the net work and thermal efficiency of the modified cycle, are formulated with respect to certain basic design parameters. Also, conditions for maximum net work are investigated, and for the modified and classical cycles, compression ratio that maximizes the net work are analytically obtained with respect to extreme temperature ratio, isothermal expansion ratio, and cutoff ratio. The results of the performance analysis of the modified dual cycle are compared with those of classical engine cycles (otto, diesel and dual cycles). In terms of net work or power, modified cycle is demonstrated to be considerably more advantegous than the classical cycles. In terms of thermal efficiency, modified cycle performs better than dual and diesel cycle, but falls short slightly of the otto cycle.
\end{abstract}

Keywords: Performance analysis, endoreversible, modified cycle, Dual cycle, net work, thermal efficiency. 


\section{Introduction}

The studies concerning the internal combustion engines have focused on increasing the performance and on reducing emission. A number of these studies include performance analysis of internal combustion engine cycles. In these studies, net work/power, thermal efficiency, power density, exergy, and ecological performance are taken as the objective function to optimize design parameters. As internal combustion engine cycles, Otto, Diesel, Atkinson, Dual, Miller, and Dual-Miller. Klein [1] compared compression ratios and thermal efficiencies at the maximum net work conditions for an ideal standard-air otto and diesel cycles. His results showed that the compression ratio at the maximum net work of the diesel cycle is higher than that of the otto cycle for the same design parameters. Taking the net work output of the diesel cycle as the objective function, Blank and $\mathrm{Wu}$ [2] optimized the cut-off ratio. Orlov and Berry [3] analytically determined upper bounds of power and efficiency of an internal combustion engine by considering finite size heat exchange. By taking into account the irreversibilities during expansion and compression, Aragon-Gonzalez et al. [4] studied the maximum work and efficiency of the otto cycle. Leff [5] investigated thermal efficiency at maximum net work conditions for Otto, Diesel, Joule-Bryton, and Atkinson cycles. Taking power and power density as the objective functions for the Atkinson cycle, Chen et al. [6] determined optimal design parameters, which resulted in smaller and more efficient engines. Lin et al. [7] applied the same objective functions to standard-air otto and dual cycles. Al-Sarkhi et al. [8-9] analyzed the performance of the reversible and irreversible Miller cycle. Rinaldini et al. [10] applied Miller cycle to a high-speed diesel engine and minimized the NOx emission. Gonca and Sahin [11] carried out performance analysis for irreversible modified dual cycle consisting of five processes with one isothermal process.

This study presents performance analysis of the endoreversible modified dual cycle consisting of five processes with an isothermal process (as characterized by the processes 1 $2-3 m-4 m-5 m-1$ in fig. 1). Net work is taken as the objective function to optimize basic design parameters for the modified dual cycle. Modified cycle is compared with classical cycles in terms of their performance analysis results. This study provides a new perspective on the investigation of endoreversible modified dual cycle.

\section{Theoretical Performance Analysis}

In this section, thermodynamic analysis has been performed by assuming that working fluid is standard air for the modified cycle. Demonstration of the modified cycle and comparison with the other classical cycles is presented in Fig. 1.

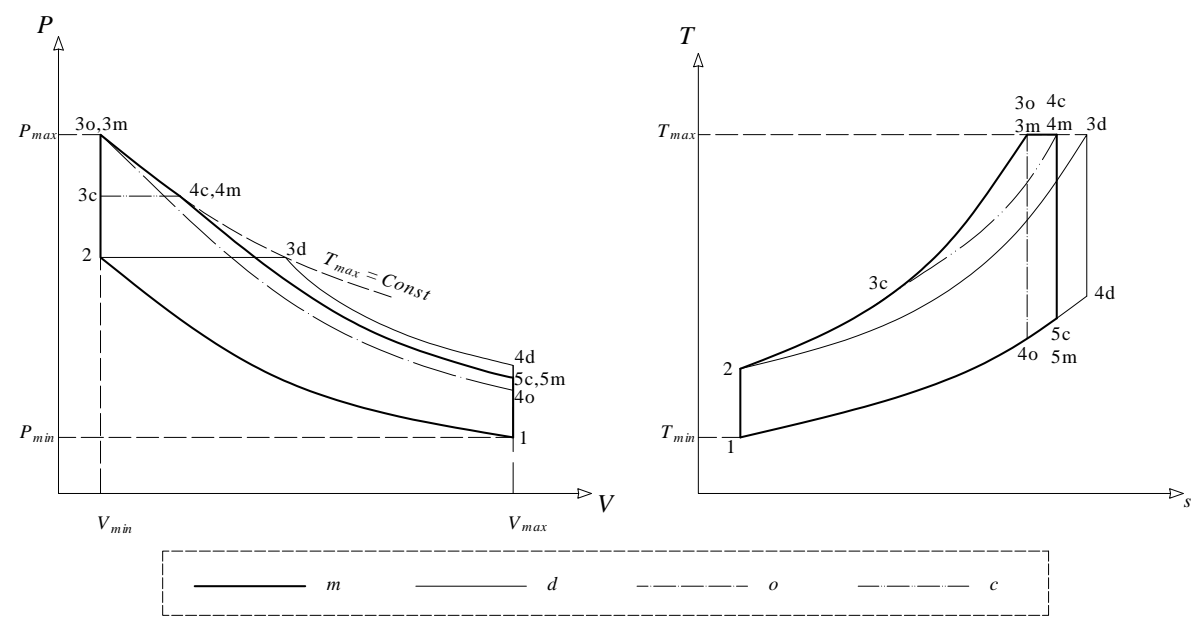

Fig. 1. $P-v$ and T-s diagrams for mentioned cycles (modified: $1-2-3 m-4 m-5 m-1$,otto: $1-2-3 o-4 o-1$, diesel: $1-2-3 d-4 d-1$, dual: $1-2-3 c-$ 4c-5c-1) for the modified cycle, dual cycle, otto cycle, and diesel cycle. 


\subsection{Theoretical Performance Analysis of Modified Cycle}

As seen in fig. 1, for the modified cycle (1-2-3m-4m-5m-1), heat input occurs at the isothermal and isovolumetric process compared to heat input in the classical dual cycle which occurs at isovolumetric and isobaric processes.

The input heat during 2-3m (isovolumetric process) can be represented as follows:

$Q_{i n, 1}=m C_{V}\left(T_{3 m}-T_{2}\right)=m C_{V}\left(T_{\max }-T_{2}\right)$

The second heat input process occurs at $3 \mathrm{~m}-4 \mathrm{~m}$ (the isothermal process). This can be derived into the following:

$\mathrm{Q}_{\text {in }, 2}=\mathrm{mRT}_{\max } \ln \left(\frac{V_{4}}{V_{3}}\right)$

$\frac{V 4}{V 3}$ can be defined as isothermal expansion ratio and can be shown by $\rho_{\mathrm{T}}$. The previous equation can be rewritten as follows:

$\mathrm{Q}_{\text {in }, 2}=\mathrm{mRT}_{\max } \ln \left(\rho_{\mathrm{T}}\right)$

The output heat at 5m-1 (isovolumetric process) can be written as follows:

$\mathrm{Q}_{\text {out }}=\mathrm{mC}_{\mathrm{v}}\left(\mathrm{T}_{5 \mathrm{~m}}-\mathrm{T}_{1}\right)=\mathrm{mC}_{\mathrm{v}}\left(\mathrm{T}_{5 \mathrm{~m}}-\mathrm{T}_{\text {min }}\right)$

Input and output heat equations can be expressed by the basic design parameters, $\alpha$ (extreme temperature ratio) $=\frac{T_{\max }}{T_{\min }}, \varepsilon$ $($ compression ratio $)=\frac{V_{\max }}{V_{\min }}, \rho_{\mathrm{T}}($ isothermal expansion ratio $)=\frac{V_{4 m}}{V_{3 m}}$
$\mathrm{Q}_{\mathrm{in}, 1}=\mathrm{mC}_{\mathrm{v}} \mathrm{T}_{\min }\left(\alpha-\varepsilon^{k-1}\right)$

$\mathrm{Q}_{\text {in }, 2}=\mathrm{mC}_{\mathrm{v}} \mathrm{T}_{\min } \alpha(\mathrm{k}-1) \ln \left(\rho_{\mathrm{T}}\right)$

$\mathrm{Q}_{\text {out }}=\mathrm{mC}_{\mathrm{v}} \mathrm{T}_{\min }\left[\alpha\left(\frac{\rho_{\mathrm{T}}}{\varepsilon}\right)^{k-1}-1\right]$

Dimensionless net work can be expressed as follows:

$$
\bar{W}_{\text {net }}=\frac{Q_{\text {in }, 1}+Q_{\text {in }, 2}-Q_{o u t}}{\mathrm{mC}_{v} \mathrm{~T}_{\min }}
$$

Replacing Qin,1, Qin,2 and Qout with eq. 5, 6, 7 in eq.8:

$\bar{W}_{\text {net }}=\left(\alpha-\varepsilon^{k-1}\right)+\alpha(k-1) \ln \left(\rho_{\mathrm{T}}\right)-\left(\alpha\left(\frac{\rho_{\mathrm{T}}}{\varepsilon}\right)^{k-1}-1\right)$

Thermal efficiency of the modified cycle can be calculated as follows:

$\eta_{\text {mod }}=1-\frac{Q_{\text {out }}}{Q_{\text {in, } 1}+Q_{\text {in }, 2}}$

$\eta_{\bmod }=1-\frac{\alpha\left(\frac{\rho_{\mathrm{T}}}{\varepsilon}\right)^{k-1}-1}{\left(\alpha-\varepsilon^{k-1}\right)+\alpha(k-1) \ln \left(\rho_{\mathrm{T}}\right)}$

The derivative of net work (dimensionless) with respect to the compression ratio:

$\frac{d \bar{W} n e t}{d \varepsilon}=-(k-1) \varepsilon^{k-2}+\frac{\alpha \rho_{\mathrm{T}}{ }^{k-1}(k-1)}{\varepsilon^{k}}$

To find the $\varepsilon$ for the maximum net work, the zero of the derivative, which is $\varepsilon$ for the maximum net work, can be obtained as:

$\varepsilon^{*}=\left(\sqrt{\alpha \rho_{\mathrm{T}}^{k-1}}\right)^{\frac{1}{k-1}}$

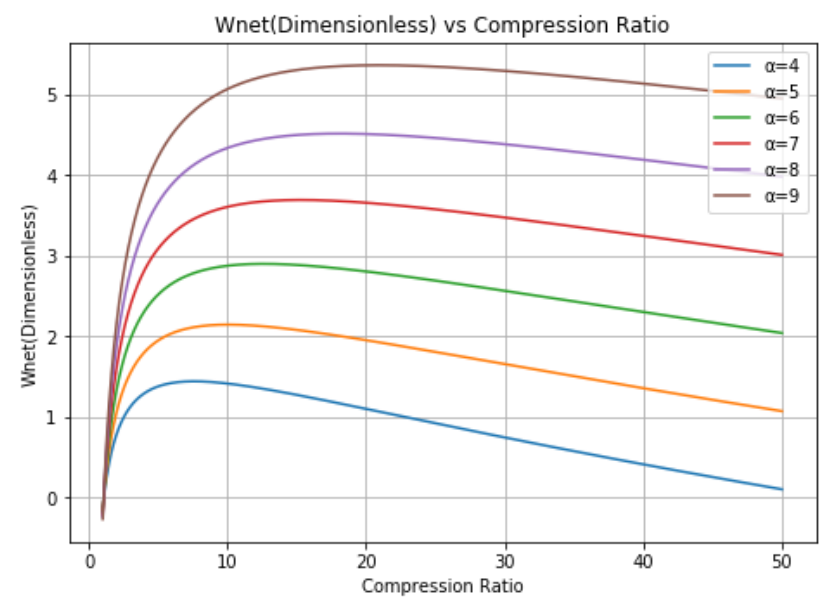

Fig. 2. The variation of dimensionless net work with respect to compression ratio of modified cycle for different extreme temperature ratios for $\rho_{\mathrm{T}}=1.8$ 


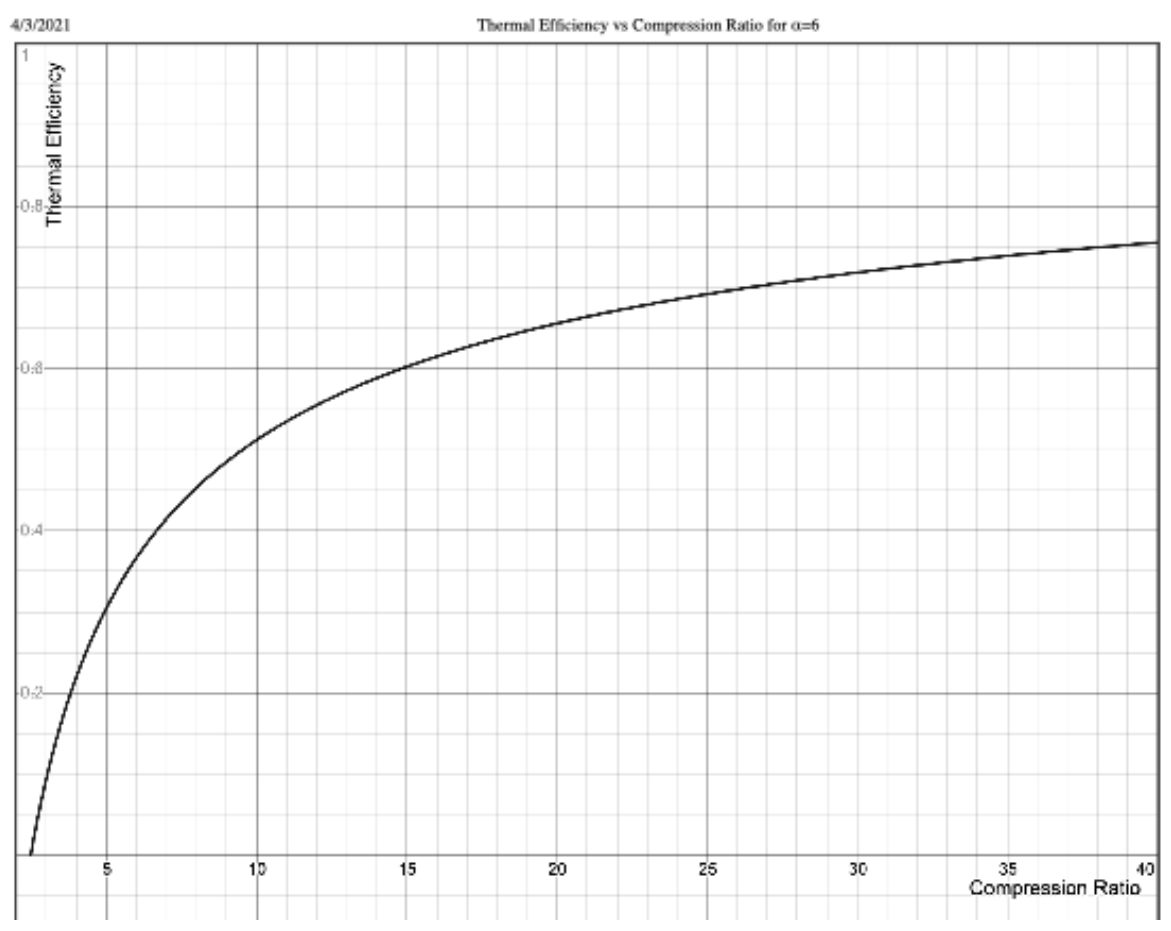

Fig. 3 The variation of thermal efficiency with respect to compression ratio of modified cycle, for $\alpha=6$ and $\rho_{\mathrm{T}}=1.8$

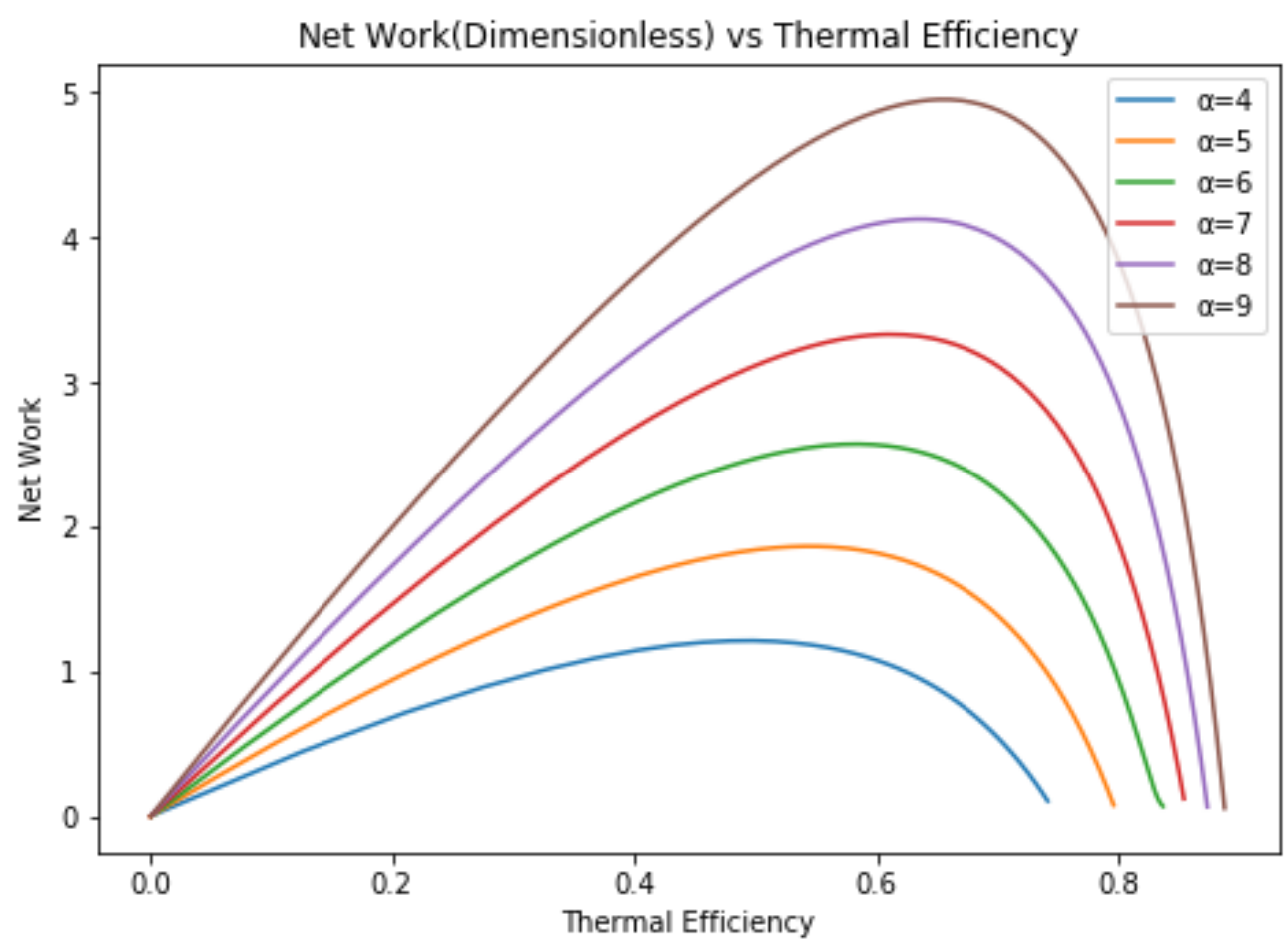

Fig. 4. The variation of net work with respect to thermal efficiency of modified cycle for different extreme temperature ratios for $\rho_{\mathrm{T}}=$

The graphs of dimensionless net work vs compression ratio, thermal efficiency vs compression ratio, and dimensionless net work vs thermal efficiency are presented in fig. 2, 3, and 4, respectively.

\subsection{Theoretical Performance Analysis Results for Classical Cycles}

Dimensionless network and thermal efficiency of the otto, diesel and dual cycles can be respectively given as follows 
(different from the modified cycle, $\rho$ is defined as the isobaric expansion ratio or the cut-off ratio) [12]:

$\bar{W}$ net, o $=\left(\alpha-\varepsilon^{k-1}\right)-\left(\frac{\alpha}{\varepsilon^{k-1}}-1\right), \eta_{\mathrm{o}}=1-\frac{1}{\varepsilon^{\mathrm{k}-1}}$

$\bar{W}$ net, di $=\mathrm{k}\left(\alpha-\varepsilon^{k-1}\right)-\left(\frac{\alpha^{k}}{\varepsilon^{\left(k^{2}-k\right)}}-1\right), \eta_{\mathrm{di}}=1-\frac{\left(\left(\frac{\alpha}{\varepsilon^{k-1}}\right)^{k}-1\right)}{\mathrm{k} \varepsilon^{k-1}\left(\frac{\alpha}{\varepsilon^{k-1}}-1\right)}$

$\bar{W}$ net, du $=\left(\frac{\alpha}{\rho}-\varepsilon^{k-1}\right)+\mathrm{k} \alpha\left(1-\frac{1}{\rho}\right)-\left(\alpha \frac{\rho^{k-1}}{\varepsilon^{k-1}}-1\right), \eta_{\mathrm{du}}=$ $1-\frac{\left(\alpha \frac{\rho^{k-1}}{\varepsilon^{k-1}}-1\right)}{\left(\frac{\alpha}{\rho}-\varepsilon^{k-1}\right)+\mathrm{k} \alpha\left(1-\frac{1}{\rho}\right)}$

The optimum compression ratio which gives the maximum net work for otto, diesel and dual cycles can be respectively calculated as:

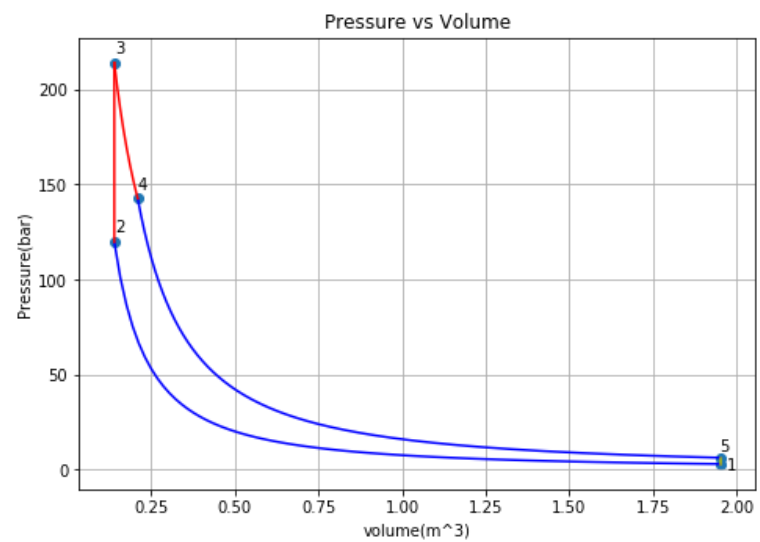

Fig 5 a. P-V diagram of the modified cycle based on design parameters presented in table 1.

Fig. 5 b. T-S diagram of the modified cycle based on design parameters presented in table 1 .

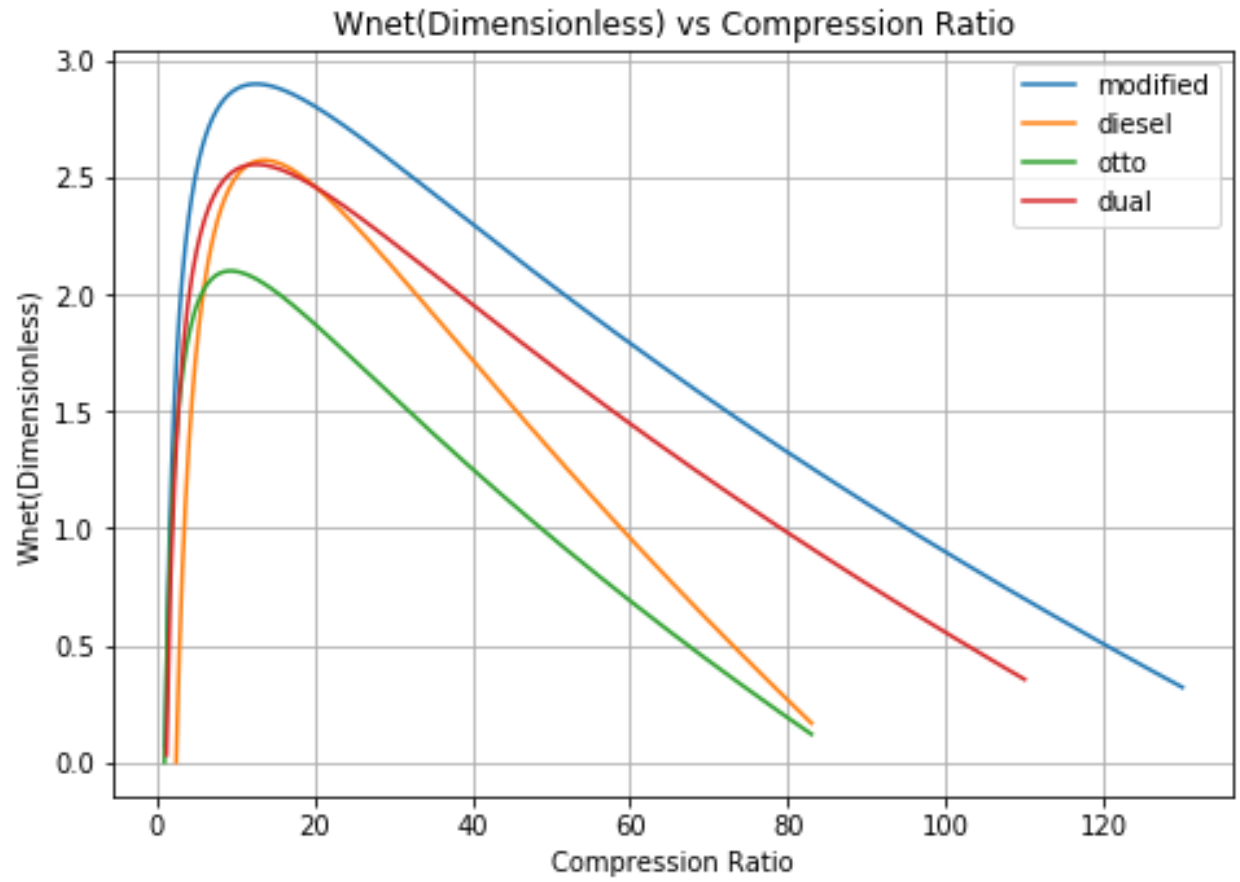

Fig. 6. The variation of net work with respect to compression ratio of mentioned cycles for $\rho$ and $\rho_{\mathrm{T}}=1.8$ and $\alpha=6$. 


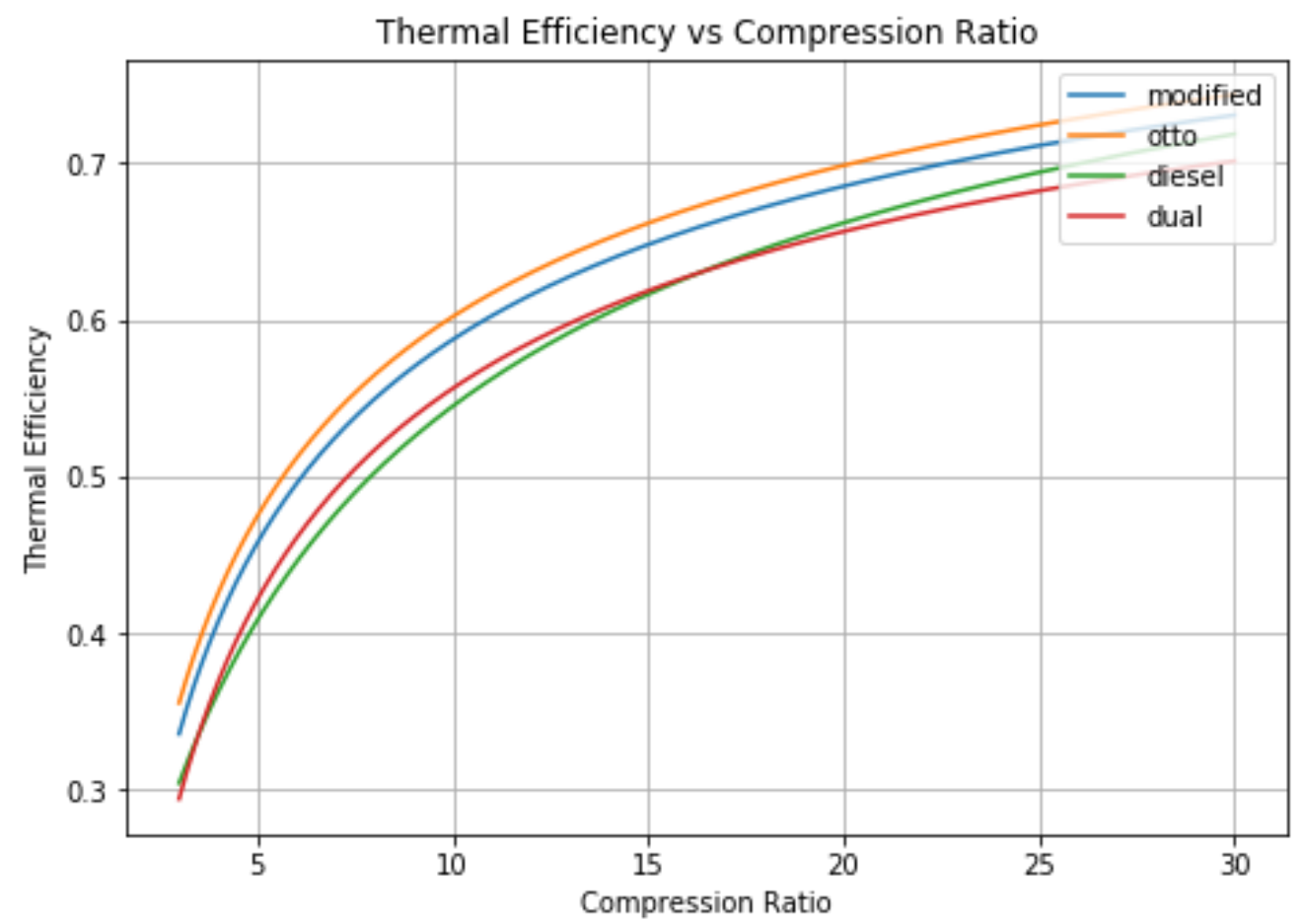

Fig. 7. The variation of thermal efficiency with respect to compression ratio of mentioned cycles for $\rho$ and $\rho_{\mathrm{T}}=1.8$ and $\alpha=6$.

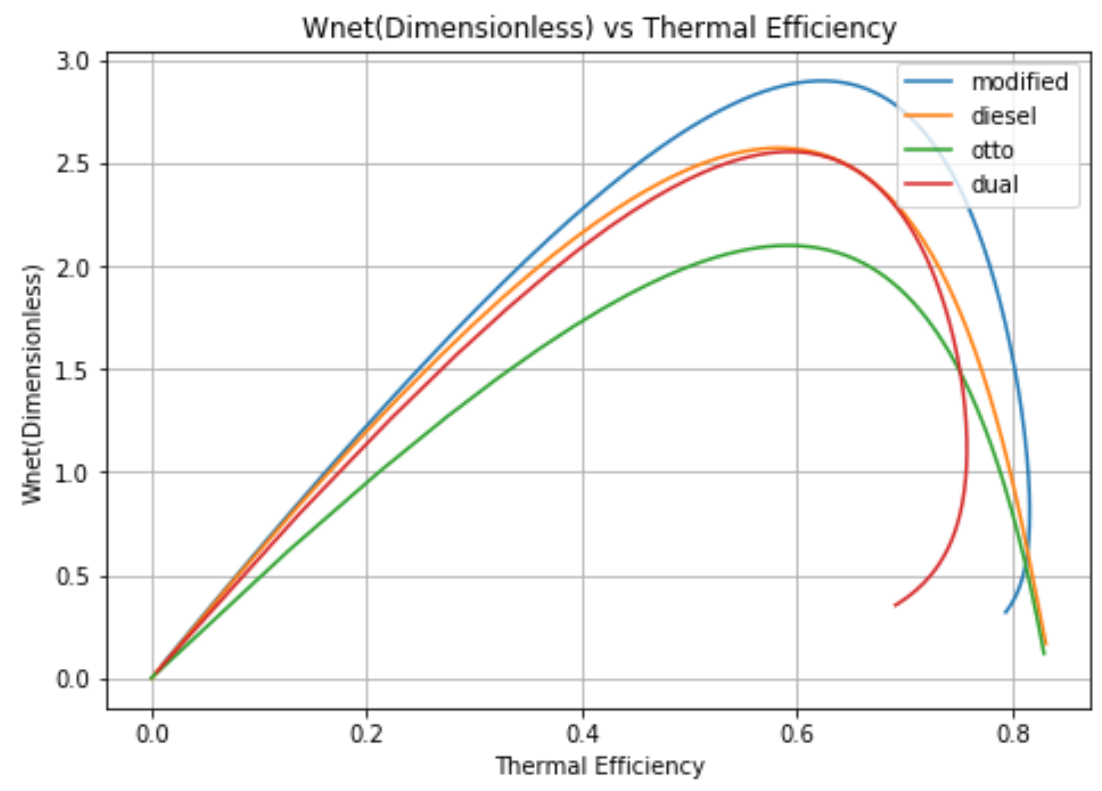

Fig. 8. The variation of dimensionless net work with respect to thermal efficiency of mentioned cycles for $\rho$ and $\rho_{\mathrm{T}}=1.8$ and $\alpha=6$.

\subsection{Numerical Performance Calculation for Modified Cycle and Classical Cycles}

Based on the basic design parameter values in table 1, $\mathrm{P}-\mathrm{V}$ and T-S diagrams of the modified cycle are drawn as seen in fig. $5 \mathrm{a}$ and $5 \mathrm{~b}$.

Table 1. Basic design parameters

\begin{tabular}{|c|c|c|c|c|c|c|c|}
\hline $\mathrm{T}_{\min }$ & $\mathrm{T}_{\max }$ & $\alpha$ & $\mathrm{V}_{\max }$ & $\mathrm{V}_{\min }$ & $\varepsilon$ & $\mathrm{P}_{0}\left(\mathrm{P}_{\min }\right)$ & $\rho$ and $\rho_{T}$ \\
\hline $323 \mathrm{~K}$ & $1704 \mathrm{~K}$ & 5.28 & $1.95 \mathrm{~m}^{3}$ & $0.14 \mathrm{~m}^{3}$ & 13.93 & $3 \mathrm{bar}$ & 1.5 \\
\hline
\end{tabular}

For the modified cycle, integral calculations for the cycle area gives $3112 \mathrm{~kJ}$ as the net work. The cycle thermal efficiency is calculated as $64.3 \%$.

Net work and thermal efficiency for the classical cycles (dual, diesel, and otto) are calculated similarly: considering as $C_{P}=1.005 \mathrm{~kJ} / \mathrm{kg} . \mathrm{K}, C_{V}=0.718 \mathrm{~kJ} / \mathrm{kg} . \mathrm{K}$, specific heat ratio, $\mathrm{k}=C_{P} / C_{V}$. Also, to draw the T-S diagram of the modified cycle, mass is taken as $1 \mathrm{~kg}$. 


$$
\begin{array}{ll}
\mathrm{W}_{\text {net, dual }}=2687 \mathrm{~kJ} & \eta_{\text {dual }}=62.6 \% \\
\mathrm{~W}_{\text {net, diesel }}=2769 \mathrm{~kJ} & \eta_{\text {diesel }}=60 \% \\
\mathrm{~W}_{\text {net, otto }}=2149 \mathrm{~kJ} & \eta_{\text {otto }}=65.13 \%
\end{array}
$$

\section{Results and Discussion}

As can be seen in fig. 2, both net work and the compression ratio at the maximum net work $\left(\varepsilon^{*}\right)$ increases as extreme temperature ratio $(\alpha)$ increases. This result is clearly seen in eq. 13. The thermal efficiency of the modified cycle is increasing at slower rate as the compression ratio increases (fig. 3). In fig. 4, the relationship between the net work and thermal efficiency for the modified cycle can be seen. As seen in the figure, as $\alpha$ increases, both thermal efficiency and net work increases. On the other hand, for a specific $\alpha$ value, maximum thermal efficiency is greater than the thermal efficiency at maximum net work $\left(\eta_{\max }>\eta_{m w}\right)$. Additionally, for a specific $\alpha$ value, maximum net work is greater than the net work at maximum thermal efficiency $\left(W_{\max }>W_{\text {me }}\right)$. Therefore, optimum design conditions should be determined considering net work and thermal efficiency together. For the optimum design conditions, following intervals can be given:

$$
\eta_{\text {max }}>\eta_{\text {opt }}>\eta_{\text {mw }} \quad W_{\text {max }}>W_{\text {opt }}>W_{\text {me }}
$$

The endoreversible modified dual cycle has been compared with the other internal combustion engine cycles (otto, diesel and dual) in terms of thermal efficiency and dimensionless net work. Fig. 6 displays that modified cycle has the greatest amount of net work obtained, meaning it has the greatest power. Also, the figure displays that the compression ratio at the maximum net work for each cycle is different. However, as Fig. 7 demonstrates, thermal efficiency of the suggested modified cycle far exceeds diesel and dual cycles' efficiency but falls behind of otto cycle with a small difference. As $\alpha$ increases, both maximum net work and thermal efficiency obtained from the compression ratio for maximum work increase. Also, as compression ratio increases, thermal efficiency increases. As demonstrated in Fig. 8 for the same thermal efficiency values, modified cycle shows a significantly higher net work whilst curves for dual and diesel cycle almost overlap and are considerably higher than net work obtained from Otto cycle.

When numerical analysis is performed based on the basic design parameters given in table 1, in terms of the network, modified cycle outperformed dual cycle by $16 \%$, diesel cycle by $12 \%$, and otto cycle by $45 \%$. In terms of thermal efficiency, modified cycle outperformed dual cycle by $2.7 \%$ and diesel cycle by $7.2 \%$, but otto cycle outperformed the modified cycle by $1.3 \%$.

\section{Conclusion}

This study demonstrates that the modified dual cycle, compared to classical cyles, is considerably more advantageous in terms of power or net work. Modified cycle, considering thermal efficiency, performs better than classical dual and diesel cycles, while by a small amount falls short of Otto cycle. Additionally, the theoretical performance analysis results show that for the modified cycle, the compression ratio at the maximum net work is the same as that of the dual cycle. Due to the limited technology, an engine with the principles of modified cycle cannot be constructed since it isn't feasible to obtain an isothermal process. However, an automated system controlling the piston speed and fuel injection rate throughout the isothermal process may make the construction feasible.

\section{References}

[1]. Klein SA. An explanation for observed compression ratios in internal combustion engines. J Engng Gas Turbines Power 1991;113:511-3.

[2]. Blank DA, Wu C. The effect of combustion on a power optimized endoreversible Diesel cycle. Energy Convers Mgmt 1993;3(6):493-8.

[3] Orlov VN, Berry RS. Power and efficiency limits for internal combustion engines via methods of finite-time thermodynamics. J Appl Phys 1993;7(10):4317-22.

[4] Aragon-Gonzalez G, Canales-Palma A, Leon-Galicia A. Maximum irreversible work and efficiency in power cycles. J Phys D: Appl Phys 2000;33:1403-9.

[5] Leff HS. Thermal efficiency at maximum work output: New results for old heat engines. Am J Phys 1987;55(7): 602-10.

[6] Chen L, Lin J, Sun F, Wu C. Efficiency of an Atkinson engine at maximum power density. Energy Convers Mgmt 1998; 3(3/4):337-41.

[7] Lin J, Chen L, Wu C, Sun F. Finite-time thermodynamic performance of a dual cycle. Int J Energy Res 1999;2(9): 765-72.

[8]. Al-Sarkhi, A., Jaber, J.O., Probert, S.D., 2006. Efficiency of a Miller engine. Appl Energ, 83,pp.343-351.

[9]. Al-Sarkhi, A., Al-Hinti, I., Abu-Nada, E., Akash, B., 2007. Performance evaluation of irreversible Miller engine under various specific heat models. Int Commun Heat Mass, 34, pp.897-906.

[10]. Rinaldini, C.A., Mattarelli, E., \& Golovitchev, V.I., 2013. Potential of the Miller cycle on a HSDI diesel automotive engine. Applied Energy,112, pp.102-19.

[11] Gonca G, Sahin B. Performance investigation and evaluation of an engine operating on a modified dual cycle. International Journal of Energy Research. (In press.)

[12] Gupta H.N., 2009. Fundamentals of Internal Combustion Engines.1st Edition. PHI Learning Private Limited, New Delhi. 